ORIGINAL ARTICLE

\title{
Minimal enteral feeding, fetal blood flow pulsatility, and postnatal intestinal permeability in preterm infants with intrauterine growth retardation
}

\author{
R M van Elburg, A van den Berg, C M Bunkers, R A van Lingen, E W A Smink, J van Eyck, \\ W P F Fetter
}

Arch Dis Child Fetal Neonatal Ed 2004;89:F293-F296. doi: 10.1136/adc.2003.027367

See end of article for
authors' affiliations
.......................
Correspondence to:
Dr van Elburg, Department
of Paediatrics, Division of
Neonatology, VU
University Medical Centre,
De Boelelaan 1117,1081
HV Amsterdam, the
Netherlands;
rm.vanelburg@vumc.nl
Accepted
16 September 2003

Objective: To study the effect of minimal enteral feeding (MEF) on intestinal permeability and feeding tolerance in preterm infants with intrauterine growth retardation (gestational age $<37$ weeks, birth weight for gestational age $p<10$ ). Furthermore, to determine whether fetal blood flow pulsatility or intestinal permeability predict feeding tolerance in these infants.

Design: Randomised controlled trial.

Methods: Within 48 hours of birth, infants were randomised to MEF or no enteral feeding (NEF) for five days in addition to parenteral feeding. Intestinal permeability was measured by the sugar absorption test before (SAT1) and after (SAT2) the study. The sugar absorption test measured the urinary lactulose/ mannitol (LM) ratio after oral ingestion of a solution ( $375 \mathrm{mosm})$ containing mannitol and lactulose. Charts of all infants were assessed for measures of feeding tolerance. Fetal blood flow pulsatility index (U/C ratio) was measured within the seven days before birth.

Results: Of the 56 infants enrolled, 42 completed the study: 20 received MEF and 22 NEF. The decrease in $L M$ ratio ( $L M$ ratio $1-L M$ ratio 2$)$ was not significantly different between the two groups $(0.25 \vee 0.11$; $p=0.14)$. Feeding tolerance, growth, and incidence of necrotising enterocolitis were not significantly different between the two groups. Neither the U/C nor the LM ratio 1 predicted feeding tolerance.

Conclusions: The results suggest that MEF of preterm infants with intrauterine growth retardation has no effect on the decrease in intestinal permeability after birth. Neither fetal blood flow pulsatility nor intestinal permeability predicts feeding tolerance.

l fetal sheep with intrauterine growth retardation (IUGR) caused by placental insufficiency, fetal blood flow is redistributed. ${ }^{1}$ Blood flow to heart, brain, and adrenals is increased in compensation, while other organs including the gastrointestinal tract are relatively hypoperfused. ${ }^{2}$ Fetal blood flow pulsatility shows this effect by changes in flow velocity waveforms in the cerebral arteries and umbilical arteries. ${ }^{34}$ Flow velocity waveforms can be qualitatively analysed using the pulsatility index (PI), defined as the difference between peak systolic and end diastolic value divided by the time average velocity. ${ }^{5}$ Redistribution of fetal blood flow, also called brain sparing, is characterised by the increase in umbilical artery/middle cerebral artery PI ratio. ${ }^{6}$

As a consequence of brain sparing, preterm infants with IUGR are thought to have impaired gut function after birth, which may result in problems ranging from temporary intolerance of enteral feeding to full blown necrotising enterocolitis (NEC). The development of a suitable feeding strategy would be helped by identification of infants at risk of gastrointestinal disturbances before birth. A few studies have investigated the relation between fetal blood flow pulsatility and gastrointestinal disturbances. ${ }^{7-12}$

As enteral feeding may increase the risk of NEC, its initiation is often postponed. Minimal enteral feeding (MEF) has recently been introduced as a strategy to improve feeding tolerance and to prevent complications of prolonged parenteral nutrition, such as gut mucosa atrophy..$^{13}$ Studies of MEF in preterm infants have shown varying effects on clinical outcomes such as feeding tolerance and growth. ${ }^{14-21}$ In addition, the mechanism for the effect of MEF is not known. Assessment of the functional integrity of the small bowel, as measured by intestinal permeability to macromolecules, may help to elucidate the effect of MEF on the gut. In addition, intestinal permeability may provide a guide for timing the introduction of enteral feeding. In previous studies in children and adults, we measured intestinal permeability by the sugar absorption test (SAT) using lactulose and mannitol. ${ }^{22-24}$ In a recent study, we found that measurement of intestinal permeability by SAT is feasible in infants with a gestational age of 26-40 weeks. ${ }^{25}$ Furthermore, we found that intestinal permeability clearly decreased during the first days of life.

We hypothesised that MEF of preterm infants with IUGR has a positive effect on intestinal permeability, reflected by a larger decrease in intestinal permeability in the first days of life. To test this hypothesis, we performed a randomised clinical trial of MEF for five days. We evaluated the functional integrity of the gut, reflected by intestinal permeability, and clinical outcome, reflected by feeding tolerance, growth, and the development of NEC. Furthermore, we determined whether fetal blood flow pulsatility or intestinal permeability could predict feeding tolerance after birth.

\section{PATIENTS AND METHODS Study population}

From January 1998 to November 2000, all preterm infants with a gestational age less than 37 weeks, a birth weight

Abbreviations: MEF, minimal enteral feeding; NEC, necrotising enterocolitis; NEF, no enteral feeding; PI, pulsatility index; SAT, sugar absorption test; IUGR, intrauterine growth retardation 
$<2000 \mathrm{~g}$, and birth weight for gestational age below the tenth centile, ${ }^{26}$ admitted to the neonatal intensive care unit of the Isala Clinics location Sophia (a tertiary referral centre) were eligible to participate in the study. Exclusion criteria were major congenital anomalies and anomalies of the gastrointestinal tract. The study was approved by the ethics committee of the Isala Clinics Zwolle.

If written informed parental consent was obtained, infants were assigned randomly by selection of cards in sealed envelopes to one of two feeding groups. One group received MEF (birth weight $<1000$ g: daily $12 \times 0.5 \mathrm{ml}$ breast milk or preterm formula; birth weight $>1000$ g: daily $12 \times 1 \mathrm{ml}$ breast milk or preterm formula (Nenatal; Nutricia Nederland BV, Zoetermeer, the Netherlands)); the other group received no enteral feeding (NEF) for five days. Nursing and medical staff as well as the researchers were aware of group assignment. All infants received parenteral feeding according to the standard protocol.

The primary outcome of the study was functional integrity of small bowel as reflected by intestinal permeability. Furthermore, we assessed feeding tolerance (time to reach full enteral feeding, number of days feed withheld), growth (days to regain birth weight, weight as percentage of birth weight on day 28), and adverse outcome (NEC Bell's $\geqslant$ stage II). Finally, we determined whether fetal blood flow pulsatility (U/C ratio) or intestinal permeability (measured within 48 hours of birth) could predict feeding tolerance.

\section{Intestinal permeability}

Intestinal permeability was measured by SAT as previously described. ${ }^{25}$ In short, after instillation of the test solution ( $2 \mathrm{ml} / \mathrm{kg}$ by nasogastric tube), urine was collected for six hours. As a preservative, $0.1 \mathrm{ml}$ chlorohexidine digluconate $20 \%$ was added to the urine. Lactulose and mannitol concentrations ( $\mathrm{mmol} / \mathrm{mol}$ creatinine) were measured by gas chromatography as previously described, ${ }^{27}$ and the lactulose/ mannitol (LM) ratio was calculated. The SAT was performed before (SAT1) and after (SAT2) five days of intervention.

\section{Fetal blood flow pulsatility}

Fetal blood flow pulsatility was measured based on obstetric decisions including evaluation of (suspected) IUGR. Only blood flow pulsatility measurements of the umbilical and middle cerebral artery performed within the seven days before birth were acceptable for the study. The last measurement before birth was used for analysis. Blood flow pulsatility was measured with the pregnant woman in a semirecumbent position, using a colour Doppler ultrasound system (ATL 5000 HDI; Bothell, Washington, USA). Measurements were performed during a steady state (fetal apnoea, physiological fetal heart rate, and no fetal movements). Flow velocity waveforms were analysed by the PI, defined as the difference between peak systolic and end diastolic value divided by the time average velocity. ${ }^{5}$ Distribution of fetal blood flow was characterised by the umbilical artery/middle cerebral artery PI ratio (U/C ratio). ${ }^{6}$

\section{Data analysis}

Data were analysed using SPSS 9.0 (SPSS Inc, Chicago, Illinois, USA). Data are expressed as median values and range. Student's $t$ test and the $\chi^{2}$ test were used for statistical comparison of clinical characteristics. A Mann-Whitney U test was performed to compare LM ratios of the MEF and NEF group. Wilcoxon signed ranks test analysed the difference between SATl and SAT2. Linear regression was used to calculate the predictive value (expressed as variance) of fetal blood flow pulsatility and intestinal permeability as measures of clinical outcome. p $<0.05$ was considered significant.

\section{RESULTS}

Fifty six infants were included in the study. The flow of patients is shown in the trial profile (fig 1). The data for 14 infants were not analysed because of early transfer to another hospital, congenital cytomegalovirus infection, death before the end of the study, or insufficient urine collection during the SAT (fig 1). The median gestational age was 210 days (range 184-254) and birth weight was $900 \mathrm{~g}$ (range 6251935). The birth weight of all infants was $<$ plo. Patient characteristics were similar in the two groups (table 1).

Table 2 shows the results of the SAT. In both the NEF and MEF group, LM ratio 1 as higher than LM ratio $2(\mathrm{p}=0.006$ and $\mathrm{p}=0.001$ respectively). The decrease in LM ratio (LM ratio 1 to LM ratio 2 ) was not significantly different in the two groups $(\mathrm{p}=0.14)$. The decrease in LM ratio was due to decreased permeability to lactulose ( $\mathrm{mmol} / \mathrm{mol}$ creatinine) in both the MEF group (301 $v$ 109, p = 0.002) and NEF group $(270 v 132, \mathrm{p}=0.03)$. The decrease in LM ratio was not due to increased permeability to mannitol ( $\mathrm{mmol} / \mathrm{mol}$ creatinine) in the MEF group (741 $v$ 925, $\mathrm{p}=0.41$ ) or the NEF group $(816 v 692, \mathrm{p}=0.73)$.

Feeding tolerance, growth, and the incidence of NEC were not significantly different in the two groups (table 3). One patient in the MEF group was diagnosed with an immature bowel syndrome, requiring an ileostomy. The patient had a very long hospital stay, and time to reach full enteral feeding was 46 days. As the overall results were not different without this patient, the patient was not excluded from analysis.

Fetal blood flow pulsatility was measured in 25/42 infants. Neither the U/C ratio nor LM ratio 1 had predictive value for time to reach full feeding $\left(r^{2}=0.01, \mathrm{p}=0.55 ; r^{2}=0.07\right.$, $\mathrm{p}=0.11$ respectively)

\section{DISCUSSION}

In our randomised clinical trial in preterm infants with IUGR, we found that MEF for five days did not influence the decrease in intestinal permeability in this period compared with NEF. Furthermore, although not the primary outcome of our study, MEF had no effect on feeding tolerance or growth.

The few studies on the effect of (minimal) enteral feeding on intestinal permeability show conflicting results. ${ }^{28-31}$ This may largely be caused by differences in study design, use of different markers, and timing of intestinal permeability tests. $^{28} 29$ In a previous study, we found that intestinal permeability, as measured by the same SAT, decreased between the first test (within 48 hours of birth) and the second test (five days later) independent of gestational age and birth weight. ${ }^{25}$ This decrease in intestinal permeability may reflect rapid postnatal adaptation of the gut and may be part of the so called gut closure. Although intestinal permeability in preterm infants was not related to gestational age, intestinal permeability was higher in preterm infants than in term infants if measured within 48 hours of birth. ${ }^{25}$ Our results are in line with results of studies of Weaver $e t$ a $^{28}$ and Beach et al, ${ }^{29}$ although differences exist in study populations (gestational age, antenatal steroids, etc) and the test methods (steady state versus bolus). In contrast, the studies of Rouwet et $a l^{30}$ and Shulman et al ${ }^{31}$ showed that intestinal permeability in preterm infants increases during respectively the first 7 and 28 days after birth. Shulman et al also found that MEF decreased intestinal permeability compared with NEF. In the study of Rouwet et al, enteral feeding was postponed until 7 days age. This may explain the increase in intestinal permeability. In a study of infants $\geqslant 34$ weeks of gestation receiving extracorporeal membrane oxygenation, no adverse effect of enteral feeding on intestinal permeability was found. ${ }^{32}$ In this study, we found a similar decrease in intestinal permeability to that in our previous 


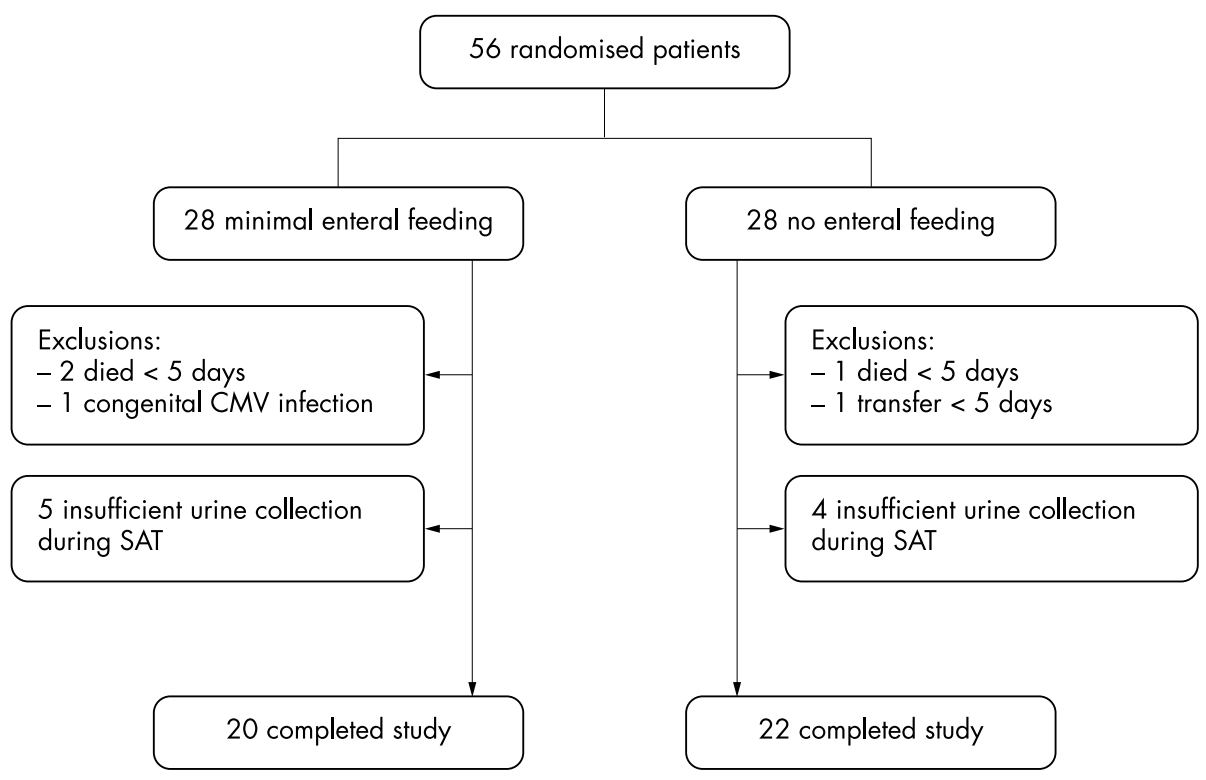

study, ${ }^{25}$ suggesting that MEF has no adverse effect on intestinal permeability.

Although not the primary outcome of our study, MEF had no effect on feeding tolerance and growth in preterm infants with IUGR. This is in contrast with other randomised clinical trials which showed a positive effect of MEF on the time to reach full enteral feeding, ${ }^{14}{ }^{21}$ length of time feed withheld, ${ }^{14}{ }^{20}$ time to regain birth weight, ${ }^{14}$ and hospital stay. ${ }^{14}$ However, a recent Cochrane Review of nine randomised clinical trials of minimal enteral nutrition in parenterally fed neonates showed no convincing evidence for the beneficial effects of MEF in very low birthweight infants. ${ }^{33}$ Moreover in this meta-analysis, the possibility that MEF might increase the incidence of NEC could not be excluded. ${ }^{33}$ In our study, there was only one case of NEC in the NEF group. Although our study was the second largest to date, a larger sample size is needed to draw conclusions about the effect of MEF on measures of clinical outcome.

Preterm infants with IUGR often have prenatal haemodynamic disturbances such as absent and/or reversed end diastolic velocities in the umbilical artery, decreased PI of the middle cerebral artery, and/or increased PI of the umbilical artery. ${ }^{44}$ These prenatal haemodynamic disturbances have been associated with increased perinatal mortality ${ }^{73}$ and morbidity such as intracranial haemorrhage, ${ }^{78}$ infant respiratory distress syndrome, ${ }^{7}$ gastrointestinal disturbances, ${ }^{11} 12$ and NEC. ${ }^{7-9}$ However, the study of Mihatsch et $a l^{10}$ did not show any association between increased umbilical artery resistance and feeding tolerance. In our study, fetal blood

Table 1 Patient characteristics

\begin{tabular}{lll}
\hline & MEF $(\mathbf{n}=\mathbf{2 0})$ & NEF $(\mathbf{n}=22)$ \\
\hline $\begin{array}{l}\text { Gestational age (weeks) } \\
\text { Birth weight (g) }\end{array}$ & $29.3(26.3-34.1)$ & $30.4(27.7-36.3)$ \\
$\begin{array}{l}\text { Asymmetric growth } \\
\text { retardation* }\end{array}$ & $13 / 20$ & $900(625-1935)$ \\
Apgar 5 min $<6$ & $2 / 20$ & $14 / 22$ \\
pH umbilical artery $<7.10$ & $1 / 20$ & $2 / 22$ \\
Mechanical ventilation & $14 / 20$ & $1 / 22$ \\
Clinical risk index for babies & $3(1-10)$ & $11 / 22$ \\
\hline
\end{tabular}

Data are expressed as median (range) or numbers.

*Defined as birth weight for gestational age $<$ pl0 and head circumference for gestational age $>$ pl0 at birth.

MEF, Minimal enteral feeding; NEF, no enteral feeding
Figure 1 Trial profile. CMV, Cytomegalovirus; SAT, sugar absorption test. 
Table 3 Feeding tolerance and growth

\begin{tabular}{llll}
\hline & $\begin{array}{l}\text { MEF } \\
(\mathbf{n}=20)\end{array}$ & $\begin{array}{l}\text { NEF } \\
(\mathbf{n}=22)\end{array}$ & $\mathbf{p}$ Value \\
\hline Days to reach full enteral feeding & $13(7-46)$ & $13(9-23)$ & 0.32 \\
Days NPO* & $0(0-15)$ & $0(0-3)$ & 0.16 \\
Days to regain birth weight & $11(5-22)$ & $10(6-28)$ & 0.78 \\
$\begin{array}{l}\text { Weight gain as \% of birth } \\
\text { weight at day 28 }\end{array}$ & $39(16-62)$ & $37(10-59)$ & 0.65 \\
NEC & $0 / 20$ & $1 / 22$ & 0.76 \\
Time in NICU (days) & $22(6-60)$ & $29(3-109)$ & 0.20 \\
\hline
\end{tabular}

Data are expressed as median (range).

*Twelve of 24 hours NPO except for the five day test period in both groups and before full feeding.

MEF, Minimal enteral feeding; NEF, no enteral feeding; NPO, nothing by mouth; NEC, necrotising enterocolitis; NICU, neonatal intensive care unit.

\section{Authors' affiliations}

R M van Elburg, A van den Berg, W P F Fetter, Department of

Paediatrics, Division of Neonatology, VU University Medical Centre,

Amsterdam, the Netherlands

C M Bunkers, R A van Lingen, E W A Smink, Department of Paediatrics, Division of Neonatology, Isala Clinics location Sophia, Zwolle, the Netherlands

J van Eyck, Department of Obstetrics, Isala Clinics location Sophia, Zwolle, the Netherlands

\section{REFERENCES}

1 Kiellmer I, Karlsson K, Olsson T, et al. Cerebral reactions during intrauterine asphyxia in the sheep. I. Circulation and oxygen consumption in the fetal brain. Pediatr Res 1974;8:50-7.

2 Peeters LLH, Sheldon RE, Jones MD, et al. Blood flow to fetal organs as a function of arterial oxygen content. Am J Obstet Gynecol 1979; 135:637-46.

3 Wladimiroff JW, Tonge HM, Stewart PA. Doppler ultrasound assessment of cerebral blood flow in the human fetus. Br J Obstet Gynaecol 1986;93:471-5.

4 Wladimiroff JW, van den Wijngaard JA, Degani S, et al. Cerebral and umbilical arterial blood flow velocity waveforms in normal and growthretarded pregnancies. Obstet Gynecol 1987;69:705-9.

5 Gosling RG, King DH. Ultrasound angiology. In: Marcus AW, Adamson L, eds. Arteries and veins. Edinburgh: Churchill Livingstone, 1975:61-98.

6 Scherion SA, Kok JH, Oosting $\mathrm{H}$, et al. Fetal and neonatal cerebral circulation: a pulsed Doppler study. J Perinatol Med 1992;20:79-82.

7 Karsdorp VH, van Vugt JM, van Geijn HP, et al. Clinical significance of absent or reversed end diastolic velocity waveforms in umbilical artery. Lancet 1994;344:1664-8.

8 Hackett GA, Campbell S, Gamsu H, et al. Doppler studies in the growth retarded fetus and prediction of neonatal necrotising enterocolitis, haemorrhage, and neonatal morbidity. BMJ 1987;294:13-6.

9 Malcolm G, Ellwood D, Devonald K, et al. Absent or reversed end diastolic flow velocity in the umbilical artery and necrotising enterocolitis. Arch Dis Child 1991;66:805-7.

10 Mihatsch WA, Polandt F, Fransz AR, et al. Early feeding advancement in very low-birth-weight infants with intrauterine growth retardation and increased umbilical artery resistance. J Pediatr Gastroenterol Nutr 2002;35:144-8.
11 Robel-Tillig E, Vogtmann C, Faber R. Postnatal intestinal disturbances in smallfor-gestational-age premature infants after prenatal haemodynamic disturbances. Acta Paediatr 2000;89:324-30.

12 Robel-Tillig E, Vogtmann C, Bennek J. Prenatal hemodynamic disturbances: pathophysiological background of intestinal motility disturbances in small for gestational age infants. Eur J Pediatr Surg 2002;12:175-9.

13 Lucas A, Bloom SR, Aynsley-Green A. Gut hormones and 'minimal enteral feeding'. Acta Paediatr Scand 1986;75:719-23.

14 Berseth CL. Effect of early enteral feeding on maturation of the preterm infants small intestine. J Pediatr 1992;120:947-53.

15 Meetze WH, Valentine C, McGuigan JE, et al. Gastrointestinal priming prior to full enteral nutrition in very low birth weight infants. J Pediatr Gastroenterol Nutr 1992;15:163-70.

16 Troche B, Harvey-Wilkes K, Engle WD, et al. Early minimal feedings promote growth in critically ill premature infants. Biol Neonate 1995;67:172-81.

17 McClure RJ, Newell SJ. Randomised controlled study of clinical outcome following trophic feeding. Arch Dis Child Fetal Neonatal Ed 2000;82:F29-33.

18 Becerra M, Ambiado, Kuntsman G, et al. Feeding VLBW infants: effect of early enteral stimulation (EES) [abstract]. Pediatr Res 1996;39:304A

19 Ostertag SG, LaGamma EF, Reisen CE, et al. Early enteral feeding does not affect the incidence of necrotizing enterocolitis. Pediatrics 1986;77:275-80.

20 Slagle TA, Gross SJ. Effect of early low-volume enteral substrate on subsequent feeding tolerance in very low birth weight infants. J Pediatr $1988 ; 113: 526-31$.

21 Dunn L, Hulman S, Weiner J, et al. Beneficial effects of early hypocaloric enteral feeding on neonatal gastrointestinal function: preliminary report of a randomized trial. J Pediatr 1988;112:622-9.

22 Uil JJ, van Elburg RM, van Overbeek FM, et al. Clinical implications of the sugar absorption test: intestinal permeability test to assess mucosal barrier function. Scand J Gastroenterol Suppl 1997;223:70-8.

23 van Elburg RM, Uil JJ, Mulder CJJ, et al. Intestinal permeability in patients with coeliac disease and relatives of patients with coeliac disease. Gut 1993:34:354-7.

24 van Elburg RM, van Aalderen WMC, Uil JJ, et al. Intestinal permeability in exocrine pancreas insufficiency due to cystic fibrosis or chronic pancreatitis. Pediatr Res 1996;39:985-91.

25 van Elburg RM, Fetter WPF, Bunkers CM, et al. Intestinal permeability in premature infants. Arch Dis Child Fetal Neonatal 2003;88:F52-5.

26 Kloosterman G. On intrauterine growth. Int Gynaecol Obstet 1970;8:895-912.

27 van Elburg RM, Uil JJ, Kokke FTM, et al. Repeatability of the sugar absorption test, using lactulose and mannitol, for measuring intestinal permeability for sugars. J Pediatr Gastroenterol Nutr 1995;20:184-8.

28 Weaver LT, Laker MF, Nelson R. Intestinal permeability in the newborn. Arch Dis Child 1984;59:236-41.

29 Beach RC, Menzies IS, Clayden GS, et al. Gastrointestinal permeability changes in the preterm neonate. Arch Dis Child 1982;57:141-5.

30 Rouwet EV, Heineman E, Buurman WA, et al. Intestinal permeability and carrier-mediated monosaccharide absorption in preterm neonates during the early postnatal period. Pediatr Res 2002;51:64-70.

31 Shulman RJ, Schanler RJ, Lau C, et al. Early feeding, feeding tolerance, and lactase activity in preterm infants. J Pediatr 1998;133:645-9.

32 Piena M, Albers MJ, van Haard PM, et al. Introduction of enteral feeding in neonates on extracorporeal membrane oxygenation after evaluation of intestinal permeability changes. J Pediatr Surg 1998;33:30-4.

33 Tyson JE, Kennedy KA. Minimal enteral nutrition for promoting feeding tolerance and preventing morbidity in parenterally fed infants. Cochrane Database Syst Rev 2000;(2):CD000504

34 Makhseed M, Jirous J, Ahmed MA, et al. Middle cerebral artery to umbilical artery resistance index ratio in the prediction of neonatal outcome. Int J Gynaecol Obstet 2000;71:119-22.

35 van Eyck J, Reuwer PJHM. Fetal and uteroplacental circulation. In: Stoutenbeek Ph, van Vught JMG, Wladimiroff JWW, eds. Echoscopie in de gynaecologie en obstetrie. Utrecht: Bunge, 1997:170-7. 